\title{
Reconstruction Using a Pedunculated Gastric Tube with Duodenal Transection After Esophagectomy and Pharyngolaryngectomy
}

\author{
Naoya Yoshida, MD, PhD, FACS ${ }^{1}$, Yoshifumi Baba, MD, PhD, FACS ${ }^{1}$, Eri Oda, MD ${ }^{1}$, Keisuke Kosumi, MD ${ }^{1}$, \\ Takatsugu Ishimoto, MD, PhD ${ }^{1}$, Masayuki Watanabe, MD, PhD, FACS ${ }^{2}$, Yukiharu Hiyoshi, MD, PhD ${ }^{1}$, \\ Shiro Iwagami, MD, PhD, FACS ${ }^{1}$, Junji Kurashige, MD, PhD ${ }^{1}$, Yasuo Sakamoto, MD, PhD, FACS ${ }^{1}$, Yuji Miyamoto, \\ MD, PhD, FACS ${ }^{1}$, Hidetaka Sugihara, MD ${ }^{1}$, Kojiro Eto, MD ${ }^{1}$, Kazuto Harada, MD ${ }^{1}$, and Hideo Baba, MD, PhD, \\ FACS $^{1}$
}

${ }^{1}$ Department of Gastroenterological Surgery, Graduate School of Medical Sciences, Kumamoto University, Chuoku, Kumamoto, Japan; ${ }^{2}$ Department of Gastroenterological Surgery, Cancer Institute Hospital of Japanese Foundation for Cancer Research, Koto-ku, Tokyo, Japan

\begin{abstract}
Background. Gastric conduit ischemia is sometimes correlated with anastomosis-related morbidities after esophagectomy and pharyngolaryngectomy. ${ }^{1-5}$ A lack of connection between the right and left gastroepiploic vessels and intraoperative injury to these vessels could cause conduit ischemia. In addition, tensioned anastomosis due to a short gastric tube also could contribute to anastomotic leaks. This report introduces a reconstruction technique using a pedunculated gastric tube with duodenal transection for these cases.

Methods. Creation of a gastric tube in the greater curvature of the stomach is performed with linear staplers. Only the right gastroepiploic vessels are preserved. The gastric tube is finally fashioned with a width of approximately $4 \mathrm{~cm}$. The peripheral right gastroepiploic vessels to the pylorus are sacrificed. After the bulbs are transected, a pedunculated gastric tube is moved, with confirmation whether it has sufficient length for anastomosis in the neck. After the anal side of the gastric tube is transected, Rouxen-Y gastrointestinal anastomosis is performed. Finally,
\end{abstract}

Electronic supplementary material The online version of this article (doi:10.1245/s10434-015-4427-1) contains supplementary material, which is available to authorized users.

(C) Society of Surgical Oncology 2015

First Received: 16 December 2014;

Published Online: 19 March 2015

H. Baba, MD, PhD, FACS

e-mail: hdobaba@kumamoto-u.ac.jp esophagogastric or pharyngogastric anastomosis is performed.

Results. Between November 2011 and September 2014, 18 patients underwent the reported reconstruction technique due to short gastric tubes in 10 patients and a lack of connection between the right and left gastroepiploic vessels in 8 patients. Anastomotic leaks occurred in three patients $(16.7 \%)$, conduit necrosis in no patients, and strictures in no patients, respectively. Two patients had an anastomotic grade 2 leak, and one patient had an anastomotic grade 3 leak.

Conclusion. The current reconstruction technique is a good alternative for patients at risk of conduit ischemia and patients with a short gastric tube after esophagectomy and pharyngolaryngectomy.

\section{REFERENCES}

1. Pacheco PE, Hill SM, Henriques SM, Paulsen JK, Anderson RC. The novel use of intraoperative laser-induced fluorescence of indocyanine green tissue angiography for evaluation of the gastric conduit in esophageal reconstructive surgery. Am $J$ Surg. 2013;205:349-52.

2. Yetasook AK, Leung D, Howington JA, Talamonti MS, Zhao J, Carbray JM, Ujiki MB. Laparoscopic ischemic conditioning of the stomach prior to esophagectomy. Dis Esophagus. 2013;26:479-86.

3. Oezcelik A, Banki F, DeMeester SR, Leers JM, Ayazi S, Abate E, Hagen JA, Lipham JC, DeMeester TR. Delayed esophagogastrostomy: a safe strategy for management of patients with ischemic gastric conduit at time of esophagectomy. J Am Coll Surg. 2009;208:1030-4.

4. Mitchell JD. Anastomotic leak after esophagectomy. Thorac Surg Clin. 2006;16:1-9.

5. Urschel JD. Esophagogastrostomy anastomotic leaks complicating esophagectomy: a review. Am J Surg. 1995;169:634-40. 